\title{
Teatro em tempos/zonas de crise: uma perspectiva teórica ${ }^{1}$
}

Theatre in times/places of crisis: a theoretical perspective

Richard Schechner ${ }^{2}$

Tradução: Rodrigo Carvalho Marques Dourado ${ }^{3}$ 


\section{Resumo}

Conferência proferida por Richard Schechner na Convenção Internacional Teatros de guerra e ações de paz. A dramaturgia comunitária e a cena do conflito, realizada em Milão entre 17 e 18 de Maio de 2002. Aborda aspectos e desdobramentos do Teatro Social realizado em diferentes situações e áreas de crise, chamando atenção para os sistemas em que essa prática está inserida e para suas funções de alívio humanitário e recuperação/fortalecimento do sentido de comunidade.

Palavras-chave: Teatros da Crise; Teatro Social; Teatro Comunitário.

\section{Abstract}

Lecture given by Richard Schechner at the International Conference War theatres and actions for peace. Community-based dramaturgy and the conflict scene, held in Milan from 17 to 18 May 2002. It addresses aspects and developments of Social Theater performed in different situations and areas of conflict by drawing attention to the systems in which this practice is inserted and to their functions that range from humanitarian relief to recovery/ strengthening the sense of community.

Keywords: Theaters of crisis; social theater; community theatre.

ISSN: 1414.5731

E-ISSN: 2358.6958

${ }^{1}$ Título original: Teatri di guerra e azioni di pace. La dramaturgia comunitaria e la scena del conflitto.

${ }^{2}$ Richard Schechner - Professor de Performance Studies da NYU e editor de The Drama Review.

${ }^{3}$ Professor Doutor da Universidade Federal de Pernambuco (UFPE). Diretor/ Fundador do Grupo Teatro de Fronteira. Desenvolve pesquisa nas áreas de

Teatro Contemporâneo, Performance, Sexualidades e Dramaturgia. rodrigodourado78@gmail.com 
1. Considere: teatros da crise e o teatro em crise. Em crise, porque o que pode fazer o teatro após o declínio de importância do teatro artístico, do teatro experimental e do teatro comercial? Não muito tempo atrás, das últimas décadas do século XIX até os anos de 1970, ou aproximadamente, os teatros artístico, experimental e comercial eram dominantes. Mas, desde os anos 1970, e crescentemente de lá para cá, o teatro da crise, o "Teatro Social", vem crescendo exponencialmente. O Teatro Social pode ser definido como: teatro com agendas sociais específicas; teatro em que a estética não é o objetivo guia; teatro fora dos domínios do sucesso comercial ou do culto ao novo que domina a vanguarda. (Não que o Teatro Social precise fugir da inovação ou nunca ser visto em um espaço comercial).

O Teatro Social conta com diferentes nomes e uma variedade de práticas, incluindo: teatro comunitário; teatro para o desenvolvimento; teatro/drama-terapia; teatro com/para marginalizados, prisioneiros, pessoas institucionalizadas; teatro em tempos de, ou logo após, guerra (como em Palestina, Kosovo, Sri Lanka, Irlanda do Norte, África do Sul e demais lugares). Há dois níveis de teatro da crise. O primeiro é o do alívio ou do teatro como remédio, como primeira ajuda social. Esse tipo de teatro dá voz aos sem voz, permite que eles expressem suas dores e esperanças, contem suas histórias com as próprias palavras e recursos. Ele também veicula pedidos de ajuda, acusa os opressores e reencena as circunstâncias específicas da crise. Esse primeiro nível do teatro da crise está bastante disseminado porque o número de pessoas em crise está crescendo. Pense em quantas zonas de guerra, prisioneiros, ocupantes de terra e pacientes existem; uma população de oprimidos, carentes ou pessoas ameaçadas. Essas pessoas consistem tanto nos fazedores quanto nos receptores do teatro social. Tais pessoas são uma população enorme e espalhada, próxima dos 100 milhões, em centenas de lugares pelo mundo.

O segundo nível é aquele das desigualdades endêmicas e conscientemente estruturadas que caracterizam os atuais, e receio que também os de amanhã, sistemas globais econômicos, políticos, sociais e militares. Não há, e continuará não havendo, ausência de pessoas oprimidas e ameaçadas. Isto é, esperanças tanto por um esforço revolucionário de sucesso que leve a uma ordem mundial justa; quanto por desenvolvimento e evolução sustentáveis na direção de uma ordem global mais justa são, no presente, infundadas. Mudanças ocorrerão, claro. Alguns dos afortunados de hoje serão as vítimas de amanhã; e alguns dos oprimidos de hoje tornar-se-ão os tiranos de amanhã. Mas a soma das desigualdades permanecerá, grosso modo, a mesma por um longo período.

Mais algumas palavras a respeito das "desigualdades estruturais". Elas são, claro, um componente necessário do capitalismo de livre mercado. Porém, mais que isso, essas desigualdades estão enraizadas na "teoria da escravidão", no fato de que não só o trabalho humano está disponível no mercado, mas também os seres humanos em sua totalidade, corpo e alma, podem ser comprados e vendidos. Do século $\mathrm{XVI}$ até a metade do século XIX, o período de escravização da África, a escravidão estava estruturada nas economias da Europa, da África e das Américas. A escravidão como um fato e a escravidão como uma teoria fez o colonialismo possível e rentável. 
Embora os asiáticos não estivessem escravizados da mesma maneira que os africanos, a teoria da escravidão guiou o relacionamento entre Europa/América do Norte e Ásia, da mesma forma que entre África e América Latina.

Nível dois. Desigualdades estruturais não podem acabar até que uma nova estrutura venha à tona. Elas não desaparecem como resultado de altas esperanças ou mesmo do dedicado trabalho das pessoas de boa vontade. Elas se vão apenas quando é vantajoso, para aqueles que operam os mecanismos do poder, substituí-las. A escravidão dos séculos XV a XIX não se acabou pelos bravos esforços dos abolicionistas, mas pela emergência da fábrica movida a máquinas, vapor e força elétrica. Escravos eram menos eficientes que os trabalhadores assalariados operando máquinas e, por isso, a escravidão foi abolida. Hoje, após o fracasso do Marxismo-Comunismo, a emergência da "nova ordem mundial" e a facilidade com que pessoas são transportadas, alguns tipos de escravidão florescem: mão de obra infantil, venda do trabalho suado, escravos domésticos e sexuais.

O Teatro Social opera tanto nos níveis medicinal quanto estrutural. O Teatro Social que está "em campo" opera no primeiro nível; o apoio para o Teatro Social "em campo" vem amplamente dos operadores no segundo nível. Essa é uma situação paradoxal. Os mesmos poderes que criam as desigualdades estruturais - que dependem das desigualdades para o poder e o lucro - também pagam por programas para aliviar a dor causada pelas desigualdades. Siga o dinheiro. De onde as Nações Unidas, as organizações governamentais e não-governamentais tiram dinheiro, uma pequena parcela do qual é usado para apoiar o Teatro Social? Quem subscreve as grandes fundações - Ford, Rockefeller, qual seja? Quem paga pelas universidades? Enquanto a mão direita coloca as populações para baixo, a mão esquerda reparte um pouco dos fundos e de outras fontes, permitindo uma certa quantidade de expressão artística e acadêmica, Teatro Social, e outros meios de aliviar os sofrimentos dos oprimidos. Se você seguir o dinheiro, logo descobrirá que os governos, as ONGs, as fundações e as universidades, etc., são os mesmos que, em outras vestes, mantêm as desigualdades estruturais. É imoral não encarar isso. "Má fé", como Jean-Paul Sartre certa vez lembrou a todos, "é o pecado das classes privilegiadas".

Isso não significa que paremos nosso trabalho. Não significa que não peguemos o dinheiro. Não significa que nosso trabalho não será, a longo prazo, parte do processo de mudança profunda nas e entre sociedades. Então, por fim, aqueles que causam e mantêm a desigualdade global, a chamada "globalização", e aqueles que incansavelmente trabalham para aliviar os sofrimentos causados pela globalização pertencem ao mesmo sistema. Não estamos em oposição absoluta; estamos apenas numa oposição de jogo. Estamos comprometidos com nossos patrocinadores como numa partida esportiva quando dois times se opõem, mas ambos pertencem à mesma liga e seguem as mesmas regras. A circunstância de estar no mesmo jogo, na mesma rede, no mesmo sistema, não nega ou faz menos necessário o trabalho feito por pessoas, a quem temos ouvido nesta conferência, e outros fazendo trabalho similar entre ameaçados, vítimas da guerra, prisioneiros e, ainda, os carentes, oprimidos e marginalizados. 
2. Que tipo de teatro tem sido descrito nessa conferência? Ele é praticado sob diferentes nomes: Teatro Aplicado, Teatro Comunitário, Drama-terapia, Teatro para o Desenvolvimento, Teatro do Oprimido, e muitos outros nomes. Tomados em conjunto, esses nomes sugerem a convergência e a emergência de um movimento de grande força e diversidade cujo objetivo básico é empoderar indivíduos, agindo com parte das comunidades para imaginar performances que expressem suas necessidades particulares em circunstâncias históricas particulares. Em outras palavras, no sistema global, o Teatro Social lida com as consequências locais da situação global.

O Teatro Social é um híbrido. Ele não é completamente importado; mas também não é totalmente nativo. $O$ primeiro pode ser pensado como teatro comercial $\mathrm{e}$ o segundo como teatro ritual. O Teatro Social não é nenhum desses dois. Tampouco se trata de um teatro que se desloca de sua origem muito bem. Somente, às vezes, é preciso tirar o Teatro Social do seu contexto de origem para convencer aqueles, nas sociedades patrocinadoras, de que tal teatro vale a pena apoiar. Às vezes, o Teatro Social sai em turnê por razões de entretenimento - quase do mesmo modo como os franceses importaram dançarinos balineses para uma exposição colonial em $\mathrm{Pa}$ ris. Mas mesmo esses tipos de apresentação podem, por vezes, servir a inesperadas motivações positivas. Os balineses fascinaram de tal modo Antonin Artaud que ele escreveu partes de $O$ Teatro e seu Duplo baseado nessa experiência e contribuiu para reformar o teatro ocidental.

Noite passada, após o jantar, muitos de nós, Guglielmo Schinina, Sue Jennings, Marina Barham, James Thompson, Roberto Ricco e eu, nos encontramos numa ocupação muito bem estabelecida na Via Morigi. Foi um desses felizes acidentes. Estávamos apenas procurando por um lugar calmo para conversar. Próximo a um restaurante, havia um pátio, caminhamos até lá e nos juntamos a um grupo de pessoas bebendo vinho e conversando. Mulheres, homens, algumas crianças. De início, pensei que era uma extensão do restaurante. Mas se tratava de uma ocupação que estava lá por quarenta anos. Sessenta pessoas no total. Os que estavam no pátio eram extremamente descontraídos, amigáveis e politicamente sofisticados. "Somos todos comunistas aqui", disse um deles. Respondi: "Costumava vestir essa camisa". Convidaram-nos a sentar. Compramos um pouco de vinho no restaurante e conversamos por algumas poucas horas. Conversamos sobre as possibilidades do movimento do Teatro Social - "Teatro Sociale". Falamos aos moradores sobre a conferência e os convidamos a tomar parte se quisessem. Reiteramos o quão abrangente o movimento do Teatro Social era; e que ele estava crescendo.

Porque estávamos arregimentando pessoas que não sabiam o que era o Teatro Social, tivemos que defini-lo. O que formulamos foi: o Teatro Social preocupa-se, primeiro, com sociedades e não indivíduos. As sociedades ocupam um espaço real e conceitual entre o indivíduo e o globo. O Teatro Social não visa ao lucro. O Teatro Social não existe apenas, ou principalmente, para fazer arte. Ele é, como coloca Sue Jennings, um teatro específico realizado para pessoas específicas em tempo e espaço específicos. Eu acrescentaria: essas pessoas, esses tempos e lugares, estão em crise. 
3. Enquanto as batalhas irrompem, as pessoas pensam, primeiro, em sobreviver. Se alguém pegasse uma arma automática e começasse a disparar balas nesta sala, a maioria de nós se esconderia. Ninguém improvisaria uma peça de teatro enquanto estivesse sob o fogo. E quando há extrema privação material - falta de água, comida, abrigo e medicamento - as pessoas pensam primeiro em adquirir esses elementos. Agora, tendo feito essas duas observações óbvias, quero questioná-las. Elas são realmente verdadeiras? Antes, durante e depois de batalhas, as pessoas rezam e performam rituais, esperando em Deus que sobreviverão. Esses não são trabalhos teatrais, mas são performances. E durantes as pausas na luta, os combatentes se divertem. Como mostra a pesquisa de Annabelle Melzer, em recente artigo na Revista Theatre (2001), durante a I Guerra Mundial diferentes tipos de performance teatral aconteciam nas trincheiras. Carnificina, entretenimento e ritual não são práticas contraditórias.

Sabemos também que nos campos de extermínio havia dois tipos de performance teatral: aquelas forçadas aos prisioneiros pelos nazistas (orquestras serenando os condenados ao entrar na câmara de gás) e apresentações subversivas realizadas pelos prisioneiros como atos de resistência e demonstração de humanidade.

Então, as circunstâncias mais extremas não acabam com a necessidade das pessoas por teatro; elas encontram formas de provê-lo e/ou ter acesso a ele. Essa necessidade vai além de encenar rituais. As pessoas querem expressar e dividir com os outros, que não têm essa experiência, como é viver na violência ou sob ameaça de violência. Ao mesmo tempo, querem algo oposto: invocar e acionar realidades alternativas. Essas realidades alternativas não são "só fingimento". Elas compõem um programa de possibilidades, de proposições para uma vida melhor. Mais, o ato de performar é, em si mesmo, viver uma "vida melhor", que inclui cooperação, criatividade, e partilhar com a comunidade e com os estrangeiros.

Se boa parte do Teatro Social afasta as pessoas dos horrores e terrores de suas vidas diárias, temos de admitir a possibilidade de que muito da "realidade comum" é imposta às pessoas. Não é algo que eles livremente escolhem. Talvez seja através do teatro (e das outras artes) que os homens aprendam sobre uma existência melhor. Talvez a arte seja o que é mais "real". Como Clifford Geertz já observou, "o homem é um animal suspenso em redes de significação que ele mesmo teceu" (1973, p.5). Isso é como sociedades em crise podem parecer se experimentadas de dentro. De fora, a situação é muito diferente.

O conceito de um "Teatro de Guerra" não é um novo conceito porque a "coisa real" envolve matar e morrer, o treinamento militar deve a um só tempo ser realista e, relativamente, inofensivo. De fato, treinamento, jogos de guerra e manobras são fundamentalmente performativos. Mas até a coisa real é performance quando vista na CNN ou noutra mídia. O valor de entretenimento do "drama da vida real", inclusive a guerra, não deve ser subestimado. Na mídia, em que a publicidade é exibida lado a lado com a notícia, as notícias assumem qualidades teatrais que vão do melodrama à tragédia, com alívio cômico ocasional. É adaptando os acontecimentos, como visto, aos tropos do drama que eles se tornam coerentes. Uma sequência específica é seguida: 1. Reportagens no local; 2. Histórias de interesse humano (dramas individuais 
ou familiares, fábulas de perda e dor); 3. Pronunciamentos políticos de "líderes mundiais" ou quem quer que esteja dirigindo a ação; 4. Interpretação dos acontecimentos por "especialistas" (geralmente na folha de pagamento das redes) - diplomatas ou generais aposentados, historiadores, colunistas de jornal, etc.

Tomada num todo, essa sequência desperta interesse e medos, torna mais pessoais eventos globais ou estratégicos, e finalmente dá sentido ao que, de outra forma, pode ser caótico ou simplesmente assustador. Claro, esse "sentido" não é objetivo, mas reflete a perspectiva - política e econômica - das redes e daqueles por trás das redes. Mesmo quando a "todos os lados" é dada a chance de se expressar, a inclinação de uma forma ou de outra é óbvia. Tudo isso se acrescenta a toda uma esfera pública teatralizada. Vivemos numa era em que nossos dramaturgos não são Shakespeare, Ésquilo, Molière, ou mesmo Dario Fo - mas a CNN e outras mídias, assessorias de imprensa, Kofi Annan da ONU, e estadistas em geral como o Secretário de Estado dos EUA (e ex-general herói) Colin Powel.

4. Há várias formas de assumir um papel no grande filme, o drama mundial. Primeiro, você pode estar on the spot ${ }^{4}$ - no lugar certo, onde a ação acontece. E também on the spot é uma expressão coloquial americana que significa, "você está sendo testado, tem que tomar decisões rápidas". Segundo, você pode estar in the spot, pego ou agarrado. Isso é diferente de ocupar o lugar onde você está no topo das coisas, no controle, tomando decisões. Estar in the spot significa que você está enredado, cercado, as coisas nalguma medida estão fora do seu controle; você não sabe o que vai acontecer em seguida. Terceiro, você pode ser from the spot, significa tanto que você está ali apenas temporariamente, pode sair quando quiser; ou que você não está on ou in the spot no momento, mas costumava estar: "Sou de lá...". Ser from the spot qualifica alguém como testemunha de primeira-mão dos eventos que você experimentou não como um forasteiro (repórter, antropólogo, voluntário), mas como um "local", um "nativo". O assassinato em 2002 do repórter do Wall Street Journal, Daniel Pearl, torna-se grande notícia porque, como jornalista, Pearl deveria ter sido tratado como alguém informando do lugar, livre para partir quando quisesse, não alguém enredado no lugar. $O$ assassinato de Pearl produz manchetes enquanto as mortes dos afegãos não.

Finalmente há aqueles assistindo em casa. Às vezes, "em casa" é a poucos quilômetros da ação e, às vezes, é a vinte e um mil quilômetros. Mas, em todo caso, quem vê se sente posicionado fora da ação, quem vê é um espectador. Quando as torres gêmeas foram atacadas em 11 de setembro, centenas de milhares de pessoas estavam "em casa" em relação a esse acontecimento. Mesmo alguns de nós muito próximos, assistindo ao vivo das ruas e apartamentos de Nova lorque, sentíamo-nos 
mais numa relação de espectador que de participante do que estava acontecendo. Muitas pessoas relataram que os eventos daquele dia pareciam "um filme".

Essas preposições - on, in, from, at - apontam para relações de lugar específicas com eventos performados. Cada preposição anuncia suas qualidades posicionais, até responsabilidades. Aqueles on the spot são participantes em virtude de seus trabalhos - soldados, equipes médicas, diplomatas, jornalistas e assim por diante. Eles não são livres para partir: seus papéis na vida demandam que permaneçam no lugar até cumprirem seus deveres. Aqueles in the spot são principalmente civis, pessoas do local, presas e cercadas. O "lugar" é maior que elas. Principalmente, aqueles in the spot desejam tanto que a crise ou a guerra fossem em outro lugar ou que eles estivessem em outro lugar. Eles querem que o lugar desapareça ou seja deslocado. As pessoas from the spot são aquelas que testemunham o que está acontecendo. Elas podem ser residentes ou repórteres, antropólogos ou câmeras espiões. Jornalistas geralmente começam as reportagens com frases como: "Estou falando para vocês do...".

Muitos trabalhadores do Teatro Social enviados para um hotspot ${ }^{5}$ estão trabaIhando tanto on the spot quanto from the spot. Eles até vão e vêm entre suas casas e o ponto onde trabalham. Com o tempo, como os jornalistas, os trabalhadores do Teatro Social são designados para diferentes lugares - tornam-se especialistas em inventar teatros de crise, teatros que lidam com a crise.

Finalmente, existe "em casa, longe do lugar". O que os jornalistas relatam, a informação disseminada em conferências a respeito do Teatro Social, romances, peças - e armazenadores de outros epifenômenos que se desenvolvem a partir das experiências de crise - funcionam, cedo ou tarde, para educar e/ou entreter as pessoas em casa. Aqueles em casa tanto de forma indireta experimentam a emoção de "estar lá" quanto agradecem aos céus por não estarem lá. $O$ terror do terrorismo é a sua habilidade de repentinamente transformar "em casa" em "no lugar".

Frequentemente, um único indivíduo desempenha vários papéis preposicionais ao mesmo tempo. Por exemplo, Marina Barham, que é palestina, é tanto from the spot, quando ela relata seu trabalho nos territórios ocupados para uma conferência sobre Teatro Social; quanto in the spot quando ela está fazendo teatro na Palestina. Ela pode até estar "em casa" de vez em quando no meio das lutas.

5. No seu nível mais imediato e local, os teatros da crise são histórias de "interesse humano". As plateias não estão mais satisfeitas em aprender sobre as ficcionais ou semi-documentais "tragédias de pessoas comuns" tais como eram oferecidas por dramaturgos desde Ibsen (Hedda Gabler) a Arthur Miller (A morte de um caixeiro-viajante). O que atrai os espectadores "domésticos" de hoje são os minidramas - trágicos, sentimentais, cômicos, farsescos, heroicos - que a vida real oferece à câmera e ao microfone. Aqueles que estão em casa normal-

${ }^{5}$ N.T: A palavra tem significados múltiplos, inclusive nas áreas ambiental e
tecnológica. Preservamos a expressão original, na falta de uma tradução que conflito, zona de acontecimentos, de interesse, de ebulição. pudesse sintetizar os significados pretendidos aqui, de "lugar quente", área de 
mente não veem os eventos subjacentes a esses minidramas em primeira mão, mas somente através do testemunho dos participantes-sobreviventes tais como recortados, editados e interpretados por jornalistas, operadores de câmera, e editores de vídeo na sede da CNN. Esses minidramas são bastante reais, mas são também ficcionalizados e embalados de tal forma para se encaixar entre peças publicitárias, os quase ubíquos comerciais de televisão. Sem os minidramas do noticiário, as pessoas não assistiriam TV; e sem os comerciais, a TV não poderia fazer lucro. É, então, necessário que as "notícias" sejam informadas de maneira a atrair os espectadores que chegam para os minidramas e ficam para os comerciais. Uma vez que há os minidramas e os comerciais, há pouquíssimo espaço para a discussão detalhada ou para a análise sócio-política e econômica.

$\mathrm{Na}$ verdade, as pessoas "em casa" não estão particularmente interessadas na análise política ou na crítica social; elas não prestam muita atenção ao quadro maior. A maioria das pessoas se envolve com os aspectos de interesse humano. Então, isso é o que domina as transmissões. Quantas vezes fomos testemunhas da mãe enlutada, da criança ferida, do soldado ou doutor heroico? O que permanece escondido, porque é abstrato ou não é um "teatro suficientemente contundente", são as operações de poder criadoras das situações que produzem a violência, que, por sua vez, faz as histórias de interesse humano. As causas são escondidas, os resultados aparecem.

6. Outra aspecto complexo diz respeito à relatividade da linguagem. $O$ "assassino" de um grupo é o "herói" do outro. "Terrorista" ou "lutador livre"? Esse não é um problema novo. O mesmo esforço para controlar o vocabulário da luta foi encenado durante as guerras de libertação (ou rebelião) colonial. Para os britânicos, o queniano Mau Mau e o israelense Irgun eram terroristas. Para os quenianos e israelenses, eles eram lutadores livres. A questão "quem são essas pessoas" não pode ser respondida de uma forma ou de outra. A resposta varia de acordo com o contexto cultural e a agenda política. Uma pessoa não pode ser um terrorista ou um lutador livre de uma maneira total e absoluta. A mesma pessoa, o mesmo ato serão ambos. Essa situação é muito diferente do estado de guerra comum em que os papéis da maioria dos combatentes são conhecidos. Pode-se dizer: "Esses soldados estão ao meu lado e aqueles são meus inimigos" e saber que o inimigo está dizendo a mesma coisa em reverso. Há uma solidez sobre isso. As identidades são confirmadas por uniformes, bandeiras e definidas em territórios em disputa. Mais que isso, há um certo respeito recíproco que acompanha o estado de guerra convencional. "Soldado" refere-se a um papel que transcende nações particulares. A palavra "soldado", nela mesma, não diz se estou me referindo a um soldado francês, chinês ou o que seja. Mas se eu digo "mártir" e nada mais com relação a Israel-Palestina, você sabe de que lado da Intifada eu estou; do mesmo jeito que você sabe de que lado estou se digo "homem-bomba".

Mas, paradoxalmente e ao mesmo tempo, nas lutas em curso em Palestina-Israel, Sri Lanka-Tamil Nadu, Caxemira Indo-Paquistanesa, Irlanda do Norte, etc., não 
há "regras de participação" claras ou campos de batalha definidos. As linhas entre civis e combatentes evaporaram. O que restou são as manobras dos Estados-Nação que parecem desajeitadas e ineficientes em relação ao que está acontecendo; uma ONU pouco eficaz; medo e ódio em todos os lados; e as histórias de interesse humano - mantendo multidões no mundo distraídas e entretidas.

7. Muitos tipos de teatro são praticados em tempos/zonas de crise. A lista que segue não pretende ser completa, mas sinalizar o que considero as mais salientes variedades de teatro em tempos de crise:

*Testemunhal: quando as vítimas contam/encenam suas histórias. A performance testemunhal pode ir das produções artísticas embelezadas, passando pelo drama-documentário (e mídia) até processos judiciais formais tais como a Comissão Verdade e Reconciliação da África do Sul. Os objetivos/funções da performance testemunhal vão desde a expressão de sentimentos, passando pela documentação de eventos até a cura de conflitos na sociedade. Algumas performances testemunhais alcançam todos esses objetivos. O poder da performance testemunhal vem da qualidade da experiência de primeira mão, da afirmação: “Eu estava lá; eu vi o que aconteceu; isso aconteceu a mim e àqueles próximos a mim". A performance testemunhal tem uma qualidade forense: a reconstrução de acontecimentos através de evidências e testemunhos oculares. Embora tocante e efetiva, a performance testemunhal sofre do "efeito rashomon", o deslizamento do relato. As pessoas e grupos recordam e dão fé de suas próprias versões dos acontecimentos. Assumir papéis como os de "vítimas", "opressores", "perpetradores", "heróis" depende em grande medida de quem está testemunhando. Isso não significa negar que grandes crimes foram e continuam sendo cometidos, mas concordar sobre o que aconteceu não é fácil.

*Acusação: durante a "guerra suja" da Argentina (1976-1983), milhares de ativistas de esquerda ou outros considerados inimigos do regime militar foram sequestrados e mortos pela polícia e pelos militares. As circunstâncias precisas de todos esses crimes não puderam, e ainda não podem, ser determinadas caso a caso. Alguns foram jogados vivos de aviões no ar sobre o Atlântico. Grávidas foram autorizadas a dar à luz e, então, assassinadas, seus bebês adotados por membros do mesmo grupo que matou as mães. Muitos foram torturados. A junta militar no poder não dizia nada a respeito dos "desaparecidos". Mesmo depois da guerra suja, os ex-comandantes, soldados e a polícia não falavam sobre o que aconteceu aos desaparecidos. Depois da restituição do Estado Civil, o novo governo estava mais interessado em "seguir em frente" do que investigar, fazer justiça, e punir os culpados direta ou indiretamente por tortura e assassinato. Na verdade, muitos dos culpados continuaram em posições de influência no governo, exército e no mercado comercial. Mas desde 1983 em diante, um grupo de "Madres" (mães) vestidas de negro marcha num círculo silencioso toda quinta-feira à tarde em torno da Praça de Maio em Buenos Aires. As "madres" exigem saber o destino de seus filhos. Elas carregam fotos dos desaparecidos, vestem lenços em que estão escritos os nomes dos desaparecidos, e apontam os dedos acusadores para o Palácio Presidencial. A aparição semanal das madres combina imagens cris- 
tãs, o poderoso culto latino-americano da Mãe e teatro político. Sua aparição solene pontualmente toda quinta-feira é uma instância muito forte do teatro de acusação.

Num nível mais oficial, tribunais de crimes de guerra são teatros de acusação. Dos tribunais de Nuremberg após a II Guerra Mundial, passando pelo espetáculo de Adolf Eichmann sentado em uma caixa de vidro à prova de bala em Jerusalém em 1961, ao atual tribunal de Slobodan Milosevic em Haia, esses tipos de tribunal são tanto teatro quanto processos judiciais. Também há um lado negro em tais "tribunais show" - como exemplificado nos tribunais de Moscou dos anos 1930, o julgamento de Ethel e Julius Rosemberg nos EUA em 1951 e o recente julgamento de judeus no Irã.

*Ação: o melhor exemplo de teatro de ação é o Teatro do Oprimido (TO) de Augusto Boal. Porque Boal escreveu tão detalhadamente sobre o TO, vou apenas brevemente tocar nele. O TO existe em muitas variações - Teatro Fórum, Teatro Invisível, Teatro Legislativo, etc. Em cada um desses, o objetivo de Boal e de seu time é permitir aos indivíduos e aos grupos que identifiquem, expressem e encenem alternativas para situações e sistemas que os estão oprimindo. No teatro legislativo, Boal, na verdade, atuou como vereador do Rio de Janeiro. Ele usou o Teatro Fórum realizado num número de bairros do Rio para identificar questões sobre as quais a população local queria chamar a atenção dos representantes eleitos. Boal foi derrotado em sua candidatura à reeleição. Seus opositores montaram uma grande campanha para derrotá-lo. Uma grande diferença entre o TO e os teatros de testemunho ou acusação é que aqueles encenando o TO não estão sempre no meio de uma crise imediata. O que os está oprimindo é frequentemente endêmico e sistemático. Às vezes, as pessoas não estão sequer cientes de que estão sendo oprimidas. Parte do trabalho do TO é acordar a consciência. Outros teatros de ação incluem uma vasta série de performances orientadas para algumas questões, do trabalho de teatro de guerrilha de grupos como o Greenpeace aos protestos orquestrados contra a Organização Mundial do Comércio. Esses grupos frequentemente provocam uma crise na ordem para chamar atenção a uma questão particular.

O teatro de ação também pode ser pura propaganda: "meu lado" está correto, "seu lado" está errado; um teatro de glorificação e denegrimento. O teatro de ação pode transmitir informação vital para a luta em curso.

*Alívio: Pessoas em crise precisam de ajuda em vários níveis. Precisam de paz, comida, água, medicamentos, abrigo e, cedo ou tarde, de empregos. Em outras palavras, precisam de uma construção comunitária. Mas junto aos projetos de longo e curto prazo, as pessoas precisam compreender e lidar com o que aconteceu. Quando essas necessidades vêm à tona, vários tipos de terapias artísticas podem ser extremamente úteis. Terapias teatrais, musicais e das artes visuais dão às pessoas não apenas ferramentas para produzir testemunhos, mas para elaborar suas experiências, transformá-las em entendimento e arte (não exatamente a mesma coisa). Às vezes, o que não pode ser expresso diretamente como "testemunho puro", pode ser compreendido pelas vias da intervenção artística. O objetivo das terapias artísticas, contudo, não é fazer "grande arte", mas usar a arte para ajudar indivíduos e comunidades. Deve-se ter isso em mente se os terapeutas não desejam, inconscientemente, transformar-se 
em exploradores.

Numa perspectiva de maior prazo, o teatro de alívio também inclui vários tipos de teatro para o desenvolvimento e teatros de base comunitária. Vários programas e informes a respeito de saúde, uso da terra, educação, e demais, podem ser efetivamente comunicados através do teatro. No mínimo, a consciência é gerada, preparando o caminho para o trabalho de diferentes especialistas. Também, e especialmente se os membros da comunidade realmente inventam as peças, ou no mínimo, atuam nelas, a construção comunitária, em si, é alcançada por meio da performance. Nos EUA, há vários exemplos desse tipo de teatro, incluindo os projetos Swamp Gravy de Colquitt, Georgia (ver: Geer, 1996), Steelbound de Bethlehem, Pennsylvania (ver: Brady, 2000), e o Community Gardens de New York (ver: Rosenthal, 2002).

*Estético: Finalmente - e quem sabe exatamente quando isso pode ter lugar? - experiências horríveis podem ser transubstanciadas em trabalhos mais "universais" e "estéticos". A tragédia grega se especializou nisso: As Troianas, de Eurípides, por exemplo. Picasso foi capaz de realizar isso com seu Guernica e Goya com seu Desastres de Guerra.

*Entretenimento: Esse pode ir da performance de um teatro, de uma dança e de uma música tradicionais até a popular e importada "tarifa magra". Esses tipos de entretenimento - tradicionais, populares e globais - são indicações de que as coisas "estão voltando ao normal". Não devemos esquecer que em tempos de crise tantos os rituais quanto o entretenimento são importantes formas de sair da rotina diária e maneiras de esquecimento temporário. Se recordar é crucial ao testemunho, à acusação, e a certas fases da cura, esquecer é necessário para o recomeço da vida diária e para a cicatrização a longo prazo. O entretenimento numa situação de crise pode ter o efeito positivo de deixar as pessoas esquecerem temporariamente onde estão e o que está acontecendo a elas. Isso é bom, esse tipo de sono e sonho coletivo.

Essas variedades de teatros em tempos/zonas de crise podem ser reduzidas a quatro grupos que têm uma relação sequencial e lógica entre eles:

1. Teatro para o alívio da angústia.

2. Teatro que toma atitude.

3. Teatro que constrói comunidade.

4. Teatro que transforma experiência em arte.

Embora esses tipos de teatro possam acontecer simultaneamente, eles muitas vezes se desdobram como uma sequência levando do alívio do tormento, através da ação, à construção de comunidades e de arte. Estão logicamente conectados porque sem aliviar a angústia e sem tomar atitude, não pode haver comunidade; e sem, no mínimo, um reflexo de comunidade não pode haver arte. 


\section{Referências}

BRADY, Sara. Welded to the Ladle: Steelbound and Non-Radicality in Community -Based Theatre. TDR, New York, v. 44, n. 2, p. 51-74, 2000.

GEER, Richard. Out of Control in Colquitt: Swamp Gravy Makes Stone Soup. TDR, New York, v. 20, n. 2, p. 103-130, 1996.

GEERTZ, Clifford. The Interpretation of Cultures. New York: Basic Books, 1973.

MELZER, Annabelle. Performances at the Western Front 1914-1918. Theater, v. 31, n. 1, Winter 2001.

ROSENTHAL, Cindy. The common green/common ground Performance Project:

The Personal, the Political, the Gardens, and NYU. TDR, New York, v. 46, n. 3, p.132$164,2002$.

Recebido em 02/05/2015 Aprovado em 07/06/2015 